\title{
Control of the setting reaction and strength development of slag-blended volcanic ash-based phosphate geopolymer with the addition of boric acid
}

\author{
Jean Noël Yankwa Djobo ${ }^{1,2}$ (D) Dietmar Stephan ${ }^{1}$
}

Received: 2 December 2020 / Revised: 4 May 2021 / Accepted: 17 May 2021 / Published online: 27 May 2021

(C) The Author(s) 2021

\begin{abstract}
This work aimed to evaluate the role of the addition of blast furnace slag for the formation of reaction products and the strength development of volcanic ash-based phosphate geopolymer. Volcanic ash was replaced by 4 and $6 \mathrm{wt} \%$ of ground granulated blast furnace slag to accelerate the reaction kinetics. Then, the influence of boric acid for controlling the setting and kinetics reactions was also evaluated. The results demonstrated that the competition between the dissolution of boric acid and volcanic ash-slag particles is the main process controlling the setting and kinetics reaction. The addition of slag has significantly accelerated the initial and final setting times, whereas the addition of boric acid was beneficial for delaying the setting times. Consequently, it also enhanced the flowability of the paste. The compressive strength increased significantly with the addition of slag, and the optimum replaced rate was $4 \mathrm{wt} \%$ which resulted in $28 \mathrm{~d}$ strength of $27 \mathrm{MPa}$. Beyond that percentage, the strength was reduced because of the flash setting of the binder which does not allow a subsequent dissolution of the particles and their precipitation. The binders formed with the addition of slag and/or boric acid are beneficial for the improvement of the water stability of the volcanic ash-based phosphate geopolymer.
\end{abstract}

Keywords Volcanic ash $\cdot$ Phosphoric acid $\cdot$ Blast furnace slag $\cdot$ Boric acid $\cdot$ Microstructure

\section{Introduction}

Aluminosilicate phosphate cement (APC) or binder is a type of acid-base cement belonging to the chemically bonded phosphate cement (CBPC) group obtained at room or slightly elevated temperature by a chemical reaction between a solid precursor (aluminosilicate powder) and an acid phosphate [1,2]. The reaction products as demonstrated in the literature are generally amorphous with a polymeric-like structure consisting mainly of repeating units of silicophosphate, aluminophosphate, silico-aluminophosphate, ferro-silicoaluminophosphate, and etc. [3-6]. Wagh suggested that because of the 3-dimensional structure of some of those phases

Jean Noël Yankwa Djobo

noeldjobo@gmail.com; noel.djobo@campus.tu-berlin.de

1 Building Materials and Construction Chemistry, Technische Universität Berlin, Gustav-Meyer-Allee 25, 13355 Berlin, Germany

2 Local Materials Promotion Authority (MIPROMALO), MINRESI, 2396, Nkolbikok, Yaoundé, Cameroon along with their amorphous polymeric structure, APC should be called phosphate geopolymer [7]. In general, the reaction product of acid phosphate-activated aluminosilicate is amorphous. This helps distinguish them from other CBPC made of metal oxide whose reaction products are crystallized. However, depending on the synthesis conditions (curing condition or addition of divalent metal oxides), semi-crystalline reaction products including struvite, monetite, brushite, and berlinite can be detected [8-10].

The interest of developing phosphate cement relies on its good early properties that make them suitable for use as a rapid repair material for the restoration of concrete structures, and the waste management by the encapsulation of heavy metals $[1,2,11]$. The synthesis of APC that sets and hardens in a shorter time at room temperature depends mainly on the chemical composition of the aluminosilicate, the type, and the dosage of the phosphate solution $[3,12$, 13]. The initial setting time of metakaolin phosphate cement ranges from $20 \mathrm{~h}$ to several days depending on the reactivity of metakaolin [13, 14], while volcanic ash-based phosphate geopolymer has an initial setting time of few minutes at room temperature [3]. However, not all volcanic ashes can 
display such a fast setting at room temperature because of the difference in their chemical and mineralogical composition. It was demonstrated that the rapid setting of volcanic ash-based phosphate geopolymer is due to the availability of divalent metals such as calcium $\left(\mathrm{Ca}^{2+}\right)$ and magnesium $\left(\mathrm{Mg}^{2+}\right)$ in the initial composition [3]. These divalent metal ions are known to be useful for accelerating the setting reaction because of their high affinity with acid phosphate $[15,16]$. Moreover, the reactivity of these divalent metal oxides depends upon their degree of crystallinity. That means if it is too reactive (high content of amorphous phase), the setting will be too fast and will not allow proper dissolution and precipitation, which is necessary for the development of products with high strength and good durability [16-18]. On the other hand, if the metal oxide is less reactive (low solubility in acid), this will delay the setting and strength development, so the control of the hardening reaction should be considered when producing phosphate cement. The addition of boric acid or borax at different percentages (borax/ $\mathrm{MgO}$ mass ratio up to $40 \%$ ) was reported effective for controlling hardening reaction [19-22]. That acid performed well on delaying the initial setting time of magnesium phosphate cement by forming a protective layer on particles of $\mathrm{MgO}$, increasing the $\mathrm{pH}$, and decreasing the temperature of the paste [21]. It is worth pointing out that the development and the understanding of the phosphate geopolymer are still at the early stage since very few papers have been published on the topic. Elsewhere the potential of using boric acid for controlling the setting and kinetic reaction of phosphate geopolymers has not yet been investigated.

This work aims at determining the reaction formation of low reactive volcanic ash-based phosphate cement modified by blast furnace slag as an accelerator, and to unveil the mechanism of the reaction of boric acid for controlling the setting reaction phosphate geopolymers.

\section{Experimental methods}

\section{Materials}

Volcanic ash (VA) was collected in the Cameroon volcanic line and ground to the final particles size $\leq 200 \mu \mathrm{m}$. OPTERRA Zement GmbH, Germany supplied ground granulated blast furnace slag (GGBFS). The mean diameter determined by laser granulometry (Mastersizer 2000 from Malvern Instruments, Worcestershire, UK) is $24.136 \mu \mathrm{m}$ and $16.046 \mu \mathrm{m}$ for VA and GGBFS respectively. Their chemical composition determined by X-ray fluorescence (PW 2400 PHILIPS instrument, Eindhoven, the Netherlands) is reported in Table 1. The mineralogical composition of both aluminosilicates is shown in Fig. 1.
Volcanic ash contains magnetite, hematite, anorthite sodian, forsterite ferroan, and augite titanian as the main minerals while the blast furnace slag is entirely X-ray amorphous. The final composition of phosphoric acid used for the synthesis of the phosphate geopolymer binder is $35 \mathrm{wt} \%$. It was obtained after dilution of the analytical grade of orthophosphoric acid 85 wt\% (VWR International $\mathrm{GmbH}$, Germany). Boric acid with $99 \%$ purity from VWR International $\mathrm{GmbH}$, Germany was used as a setting retarder.

\section{Preparation of the phosphate cement}

Two series of mixes were carried out. The first one consists of VA replaced with GGBFS at different rates, while the second mix is composed of the previous ones with the addition of boric acid $\left(\mathrm{H}_{3} \mathrm{BO}_{3}\right)$ as a setting retarder. The paste was obtained by first mixing VA and GGBFS for 2 min, and then the phosphoric acid (PA) solution is added with PA to the solid powder mass ratio of 0.45 and further mixed for 3 min using a KitchenAid. The details of different mix designs are summarized in Table 2. The formulation including $\mathrm{VA}+\mathrm{H}_{3} \mathrm{PO}_{4+}$ $\mathrm{H}_{3} \mathrm{BO}_{3}$ was dismissed as the hardening time of that mix is already long (3 days), so it is not relevant to retard its setting reaction with boric acid. Once the different pastes were obtained, they were poured into 20 -mm cubic molds and covered with a plastic foil to prevent the rapid evaporation of water. Then, the samples were stored at $20{ }^{\circ} \mathrm{C}$ and $65 \%$ relative humidity for at least $24 \mathrm{~h}$ before demolding and stored again in a plastic bag in the same conditions until the different tests were performed.

\section{Characterization of reaction products}

The initial and final setting times were determined using an automatic Vicat apparatus (Toni Technik GmbH, Berlin, Germany) according to EN 196-3.

The formation of reaction products from blended volcanic ash-based phosphate geopolymer with and without boric acid was monitored by measuring the heat flow evolution, cumulative heat of reaction, and rheological properties. The Isothermal Conduction Calorimetry (TAM Air 3 calorimeter, TA Instruments, New Castle, DE, USA) was performed at $20^{\circ} \mathrm{C}$ for $24 \mathrm{~h}$. For this test, $7 \mathrm{~g}$ of powder was mixed externally with phosphoric acid (according to the mix proportion in Table 2) for 3 min using a vortex mixer, then immediately put in the calorimeter.

The rheological properties of the binder were measured with a dynamic rheometer (Haake Rheometers, Thermo Fisher Scientific, Karlsruhe, Germany). The flow curves were recorded in rotational motion using Cylinder Sensor Systems (Z20DIN, composed of a mobile rotor and a static beaker). The test setup includes a pre-shearing phase to homogenize 
Table 1 Chemical composition of volcanic ash and GGBF slag (wt $\%$ )

\begin{tabular}{lllllllllllll}
\hline Oxides & $\mathrm{SiO}_{2}$ & $\mathrm{Al}_{2} \mathrm{O}_{3}$ & $\mathrm{Fe}_{2} \mathrm{O}_{3}$ & $\mathrm{CaO}$ & $\mathrm{MgO}$ & $\mathrm{Na}_{2} \mathrm{O}$ & $\mathrm{TiO}_{2}$ & $\mathrm{~K}_{2} \mathrm{O}$ & $\mathrm{MnO}$ & $\mathrm{P}_{2} \mathrm{O}_{5}$ & $\mathrm{LOI}$ & $\mathrm{Total}$ \\
\hline VA & 41.7 & 16.0 & 13.5 & 9.3 & 8.18 & 2.42 & 3.01 & 1.34 & 0.21 & 0.89 & 2.61 & 99.1 \\
GGBFS & 38.0 & 10.8 & 0.3 & 40.1 & 7.24 & 0.31 & 0.83 & 0.64 & 0.17 & 0.02 & - & 98.4 \\
\hline
\end{tabular}

the paste in the sample holder, followed by the measurement of the shear stress vs. shear rate. The pre-shearing phase consists of rising the shear rate from 0 to $100 \mathrm{~s}^{-1}$ within $30 \mathrm{~s}$ and decreasing it from 100 to $0 \mathrm{~s}^{-1}$ in the same period, followed by a resting time of $30 \mathrm{~s}$. The subsequent measuring phase consisted of an ascending ramp, increasing the shear rate from 0 to $100 \mathrm{~s}^{-1}$ within $60 \mathrm{~s}$ followed by a sloping ramp from 100 to $0 \mathrm{~s}^{-1}$ within $90 \mathrm{~s}$. The measurements were performed at $20^{\circ} \mathrm{C}$, and for each test, $5 \mathrm{~g}$ of paste was used.

The compressive strength evolution was measured at 3, 7, and $28 \mathrm{~d}$ according to EN 196-1 by using a compression testing machine (Toni Technik, Berlin, Germany).

The changes in the mineralogy are determined from the Empyrean PANalytical diffractometer (Malvern Panalytical Ltd., Malvern, UK) with $\mathrm{Ni}$ filter $\mathrm{CuK} \alpha$ radiation $(\mathrm{k}=$ $1.540598 \AA$ ). The binder was characterized by measuring the mass loss and phase transformation while the temperature rises by using thermal gravimetry analysis and differential scanning calorimetry (3+ SARe System, Mettler Toledo, Columbus, $\mathrm{OH}, \mathrm{USA})$. The test was performed in the temperature range $25-1000^{\circ} \mathrm{C}$ at a heating rate $5 \mathrm{~K} / \mathrm{min}$ with synthetic air flowing at $70 \mathrm{~mL} / \mathrm{min}$.

The microstructure and the chemistry of the binder were determined by using a scanning electron microscope (SEM) coupled with energy-dispersive X-ray spectroscopy (Zeiss Gemini SEM 500 NanoVP microscope, Oberkochen, Germany). The device used is equipped with a backscattered electron detector (BSD) that operates at low-vacuum mode with $15 \mathrm{kV}$ acceleration voltage.

\section{Results and discussion}

\section{Setting times}

The influence of the slag replacement rate and addition of boric on the setting times are reported in Table 2. The initial setting time (IST) and final setting times (FST) of the phosphate geopolymer with $100 \%$ volcanic ash are $6.5 \mathrm{~h}$ and $24 \mathrm{~h}$ respectively. When volcanic ash was replaced by 4 and $6 \mathrm{wt} \%$ slags, the IST and FST are shortened significantly. The mix with $6 \mathrm{wt} \%$ of slag replacement was too fast to be measured, and only the final setting time was measured and is $0.16 \mathrm{~h}$ (10 min). This may be due to the preferential fast dissolution of calcium from slag and its precipitation with the available phosphate species that accelerate the setting reaction $[3,23]$. When boric acid was added, the IST and FST were delayed to $4.5 \mathrm{~h}$ and $18 \mathrm{~h}$ respectively for the mix with $4 \mathrm{wt} \%$. For the mix with $6 \mathrm{wt} \%$ slags, the initial and final setting times were also delayed to $0.08 \mathrm{~h}(5 \mathrm{~min})$ and $0.90 \mathrm{~h}(55 \mathrm{~min})$. In literature, it was reported that the retardation effect of boric acid in the hydration of magnesium phosphate cement depends upon the dosage in the mix. With a lower dosage, it mainly acts on hindering the precipitation reaction (delay of the initial setting time) by stabilizing $\mathrm{Mg}^{2+}$ ions with the formation of the complex $\mathrm{MgB}(\mathrm{OH})_{4}{ }^{+}$which makes the $\mathrm{Mg}^{2+}$ ions less available to react with phosphate species [20], while for a higher dosage, it rather delays the dissolution reaction (delay of the final setting time) [22]. In this work, the initial and final setting times were delayed with the presence of boric acid. Therefore, one can
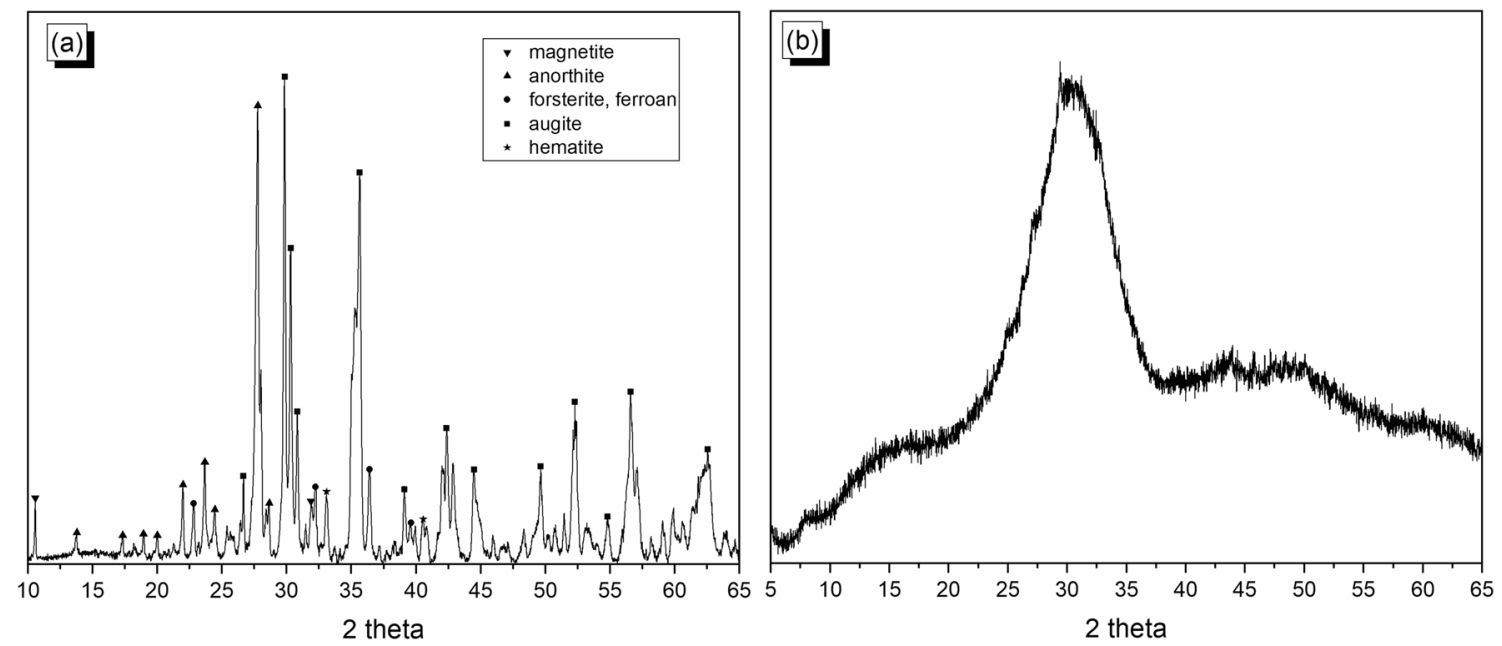

Fig. 1 X-ray patterns of a volcanic ash and $\mathbf{b}$ ground blast furnace slag 
Table 2 Details of the different mix designs and setting times

\begin{tabular}{llllll}
\hline VA (wt\%) & GGBFS (wt\%) & $\begin{array}{l}\text { Mass ratio } \\
\text { Phosphoric acid/ } \\
\text { (VA+GGBFS) }\end{array}$ & $\begin{array}{l}\text { Boric acid/ } \\
\text { (VA+GGBFS) (wt\%) }\end{array}$ & $\begin{array}{l}\text { Initial setting } \\
\text { time (h) }\end{array}$ & $\begin{array}{l}\text { Final setting } \\
\text { time (h) }\end{array}$ \\
\hline 100 & 0 & 0.45 & 0 & 6.50 & 24 \\
96 & 4 & 0.45 & 0 & 0.17 & 0.70 \\
94 & 6 & 0.45 & 0 & flash & 0.16 \\
96 & 4 & 0.45 & 5 & 4.50 & 18 \\
94 & 6 & 0.45 & 5 & 0.08 & 0.92 \\
\hline
\end{tabular}

say that the inhibition of both dissolution and precipitation of volcanic ash slag during the reaction is responsible for the delaying of the setting time.

\section{Reaction kinetics}

The effects of slag and boric acid on the reaction kinetics of the formation of volcanic ash phosphate geopolymer binder are depicted in Figs. 2 and 3. The heat flow curves (Fig. 2) display a single exothermic peak whose maximum is reached within 6 min after mixing. Similar behavior was also observed in an acid phosphate-activated high-calcium fly ash where the maximum peak of the heat evolution was reached within 2$4 \mathrm{~min}$ [24]. In the case of volcanic ash phosphate geopolymer binder, the exothermic peak corresponds to an increase in the reaction temperature [25]. This corresponds to the dissolution of the initial raw materials and the precipitation of the dissolved species to give the reaction products [3]. When slag is added to the mix, the heat of the reaction rises significantly with the increase of the slag content. That change is related to the additional heat provided by the dissolution of slag, which is rich in calcium. The latter was reported as other divalent metal oxides to generate excessive heat when mixed with an acid phosphate [26]. This sometimes leads to a reaction

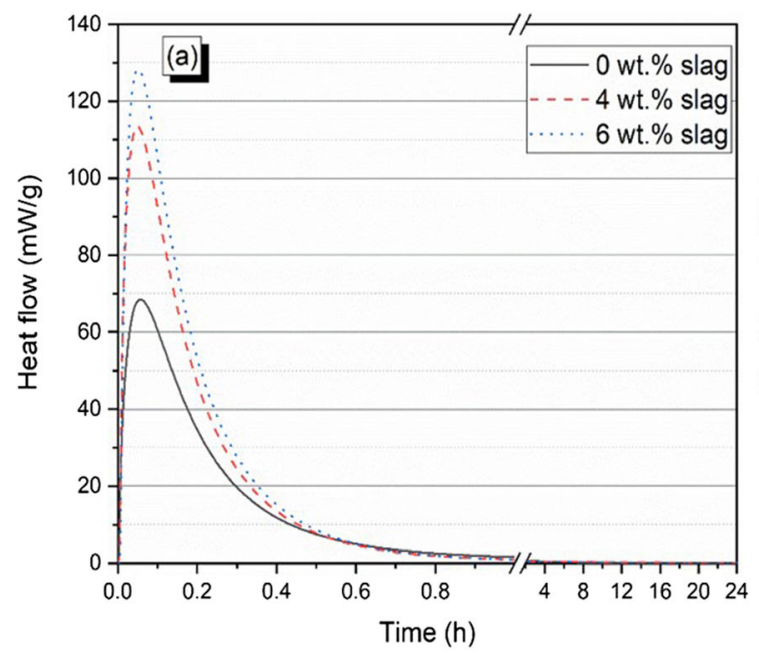

temperature of up to $95^{\circ} \mathrm{C}$ depending on the content of the reagents [27]. Knowing that the dissolution of silica and alumina is lower at room temperature, it is evident that the additional heat supplied by slag dissolution has improved the dissolution rate of volcanic ash [5, 12, 18, 28].

The addition of boric acid significantly decreased the height of the exothermic peak (Fig. 2b). A similar decrease is also observed in the total heat released after $24 \mathrm{~h}$. The total heat achieved after $24 \mathrm{~h}$ (Fig. 3a) by the slag-blended volcanic ash phosphate geopolymer binder is $83 \mathrm{~J} / \mathrm{g}, 107 \mathrm{~J} / \mathrm{g}$, and $114 \mathrm{~J} /$ $\mathrm{g}$ for samples with 0,4 , and $6 \mathrm{wt} \%$ of slag, respectively. With the addition of boric acid, the total heat released after $24 \mathrm{~h}$ (Fig. 3b) is now $74 \mathrm{~J} / \mathrm{g}, 91 \mathrm{~J} / \mathrm{g}$, and $101 \mathrm{~J} / \mathrm{g}$ for samples with 0 , 4 , and $6 \mathrm{wt} \%$ respectively. This trend translates that the addition of boric acid has decreased the rate and extent of the dissolution-precipitation reaction. This corroborates the results of the initial and final setting times. Such behavior can be explained by the fact that when all components are mixed, there is a competition between the dissolution of boric acid (endothermic process) and the dissolution of volcanic ash slag (exothermic process). It is worth noting that the reaction between boric acid $\left(\mathrm{H}_{3} \mathrm{BO}_{3}\right)$ and phosphoric acid $\left(\mathrm{H}_{3} \mathrm{PO}_{4}\right)$ gives rise to boron phosphate $\left(\mathrm{BPO}_{4}\right)$ and water [29]. This means in our case that part of the phosphoric acid was consumed for the

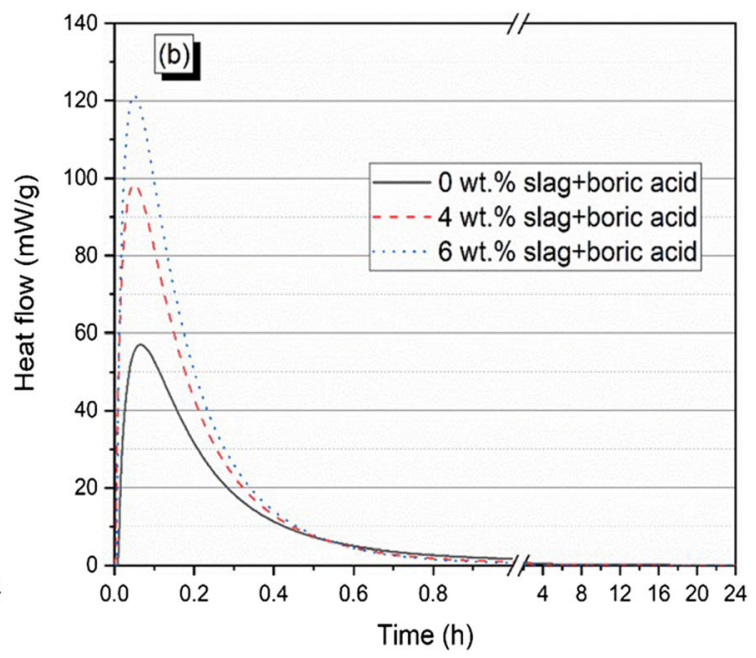

Fig. 2 Effect of blast furnace slag (a) and boric acid (b) on the heat flow evolution of slag-volcanic ash phosphate geopolymer binder 

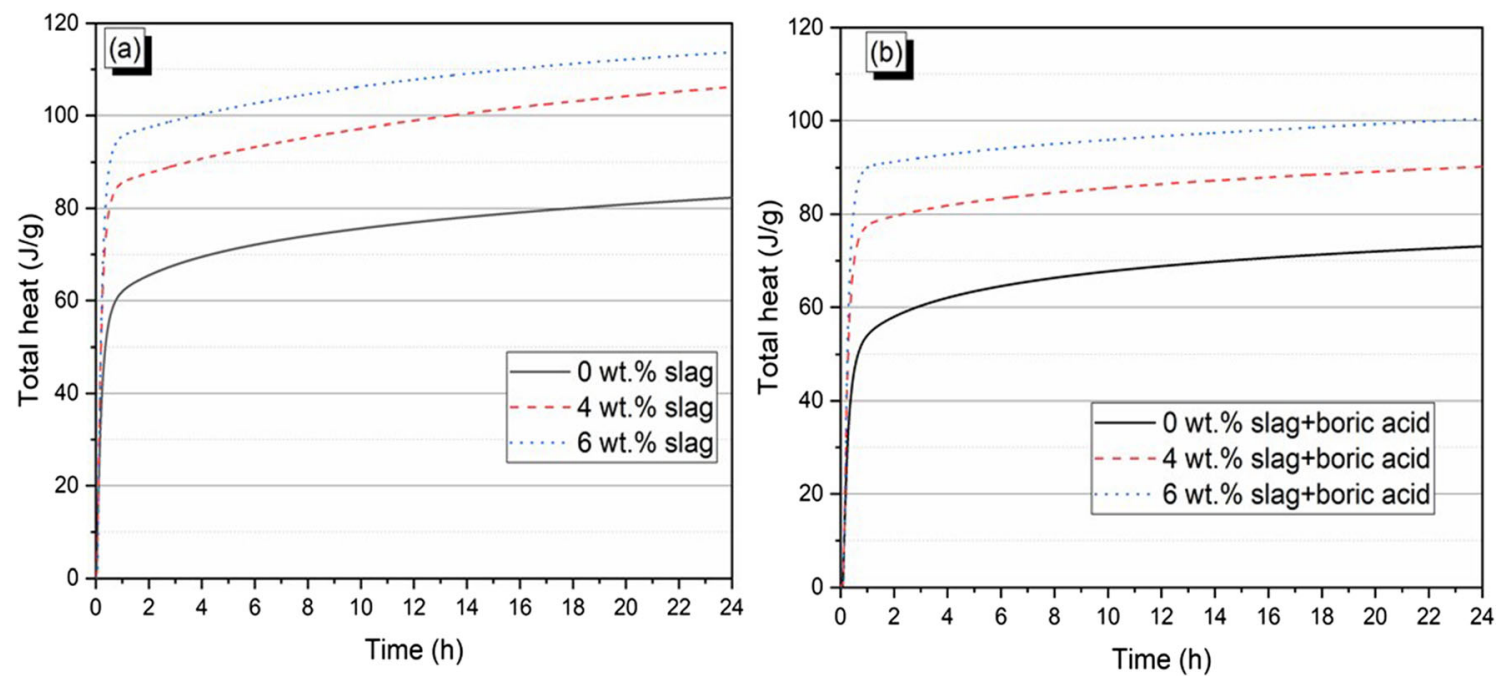

Fig. 3 Effect of blast furnace slag (a) and boric acid (b) on the total heat evolution of slag-volcanic ash-based phosphate geopolymer binder

dissolution of boric acid, which limits the availability of protons $\left(\mathrm{H}^{+}\right)$that requires for the subsequent dissolution of volcanic ash and slag. Therefore, it contributes to the decrease in reaction temperature or heat $[19,21,22]$. However, no delay was observed in the time for reaching the peak maximum of the heat released during the reaction. This indicates that the boric acid in the current system does not retard the reaction process but rather inhibits the dissolution-precipitation. This occurs because, in addition to the limited availability of protons $\left(\mathrm{H}^{+}\right)$for the dissolution of the aluminosilicate, there is a lack of sufficient phosphate species for undergoing the precipitation, so there is a reduction in the yield of the reaction products formed at the end of the process. That can be assumed as the main mechanism for controlling the setting reaction and the reaction kinetics of volcanic ash-slag phosphate geopolymer binder with boric acid.

\section{Rheological properties}

Figure 4 shows one hysteresis cycle (shear stress vs. shear rate) of different mixes. The shear stress increases nonlinearly with the shear rate, so the rheological properties were computerized by applying the non-linear fitting on the down ramp curve using the Herschel-Bulkley function. The latter consists of $\tau=\tau_{0}+K \dot{\gamma}^{n}$ (where $\tau$ is the shear stress $(\mathrm{Pa}$ ), $\dot{\mathrm{X}}$ is the shear rate $(1 / \mathrm{s}), \tau_{0}$ is the yield stress $(\mathrm{Pa}), \mathrm{n}$ is the fluidity index, and $\mathrm{K}$ is the consistency coefficient (Pa s)). The yield stress $\left(\tau_{0}\right)$ is the minimum force that requires to apply on the paste to flow [30]. In Table 3, reporting the rheological properties, the yield stress increases with slag content even after the addition of boric acid. This illustrates the high interaction among dissolved species in the mixes and the acceleration of the hardening.

The flow index (n) decreases with increasing the slag content. It describes the dependence of the viscosity to shear rate in the non-Newtonian fluid. It is worth noting that for a non-Newtonian fluid, when $n<1$, it means that the paste behaves like a shear-thinning fluid and when $n>1$, it is a shear-thickening fluid $[30,31]$. In Table 3 , the fluidity index is lower than 1 , indicating that the blended slag-volcanic ash-based phosphate geopolymer pastes behave like a shear-thinning fluid. This implies that the viscosity of the pastes increases with the decrease of the shear rate. This observation also holds for the mixes with boric acid. However, the fluidity index of blended slag-volcanic ash-based phosphate geopolymer pates remains lower than those with boric acid and decreases with the slag content, so the addition of boric acid is beneficial for lowering the viscosity of the paste. This agrees with the literature where an improvement of the flowability of the paste of magnesium potassium phosphate cement with increasing dosage of boric acid was observed [21].

\section{Compressive strength development}

The results of the compressive strength evolution in dry conditions and after immersion in water for $24 \mathrm{~h}$ are depicted in Fig. 5. The compressive strength increases over time and is optimal when volcanic ash is replaced by $4 \mathrm{wt} \%$ of slag. Further increase in the replacement rate leads to a decrease in the compressive strength. After immersion into water for $24 \mathrm{~h}$, the compressive strength drops sharply by up to $40.3 \%$. However, the mixes with slag show the maximum $28 \mathrm{~d}$ strength loss of $36.4 \%$ and $24.7 \%$ respectively with $4 \mathrm{wt} \%$ and $6 \mathrm{wt} \%$ of volcanic ash replacement. This demonstrates that the addition of slag is beneficial for improving the water stability of the volcanic ash phosphate geopolymer binder when compared with the reference sample. That is because slag also takes part in the reaction by consuming some proton $\left(\mathrm{H}^{+}\right)$for its dissolution and the dissolved calcium condenses 
Table 3 Rheological properties of slag-blended volcanic ash phosphate cement

\begin{tabular}{lllll}
\hline $\begin{array}{l}\text { VA } \\
(\mathrm{wt} \%)\end{array}$ & $\begin{array}{l}\text { GGBFS } \\
(\mathrm{wt} \%)\end{array}$ & $\begin{array}{l}\text { Boric acid/ } \\
\text { (VA+GGBFS }) \\
(\mathrm{wt} \%)\end{array}$ & $\begin{array}{l}\text { Yield stress, } \\
\tau_{0}(\mathrm{~Pa})\end{array}$ & $\begin{array}{l}\text { Fluidity } \\
\text { index, } \mathrm{n}\end{array}$ \\
\hline 100 & 0 & 0 & 0.393 & 0.856 \\
96 & 4 & 0 & 0.664 & 0.843 \\
94 & 6 & 0 & 1.426 & 0.834 \\
96 & 4 & 5 & 1.032 & 0.896 \\
94 & 6 & 5 & 1.358 & 0.847 \\
\hline
\end{tabular}

with the phosphate ions to form water-stable reaction phases [12, 32-34], whereas the flash reaction of calcium with acid phosphate does not allow a good subsequent dissolution of volcanic ash when replaced by a higher content of slag. It is worth noting that the calcium-containing phases are preferentially dissolved in phosphoric acid at the early reaction stage and precipitate with the phosphate species to form amorphous calcium phosphate phases $[9,24]$, so the addition of slag will induce the formation of a high amount of calcium phosphate phase. The latter was described as responsible of the flash initial setting time reported in Table 2 for phosphate binder with $6 \mathrm{wt} \%$ of slag. Furthermore, it was reported that aluminum and iron are the main elements contributing to the strength development of volcanic ash phosphate binder [3], so the limitations in the availability of these elements during the reaction process will hinder the compressive strength development.

The effect of the addition of boric acid on the strength development of slag-blended volcanic ashbased phosphate geopolymer is depicted in Fig. 6. The $28 \mathrm{~d}$ compressive strength is the most affected by the addition of boric acid, with a compressive strength loss (as regards to the strength of the mixes without boric acid, Fig. 5) of $46.4 \%$ and $36 \%$ respectively for the mixes with 4 wt $\%$ and 6 wt $\%$ of volcanic ash
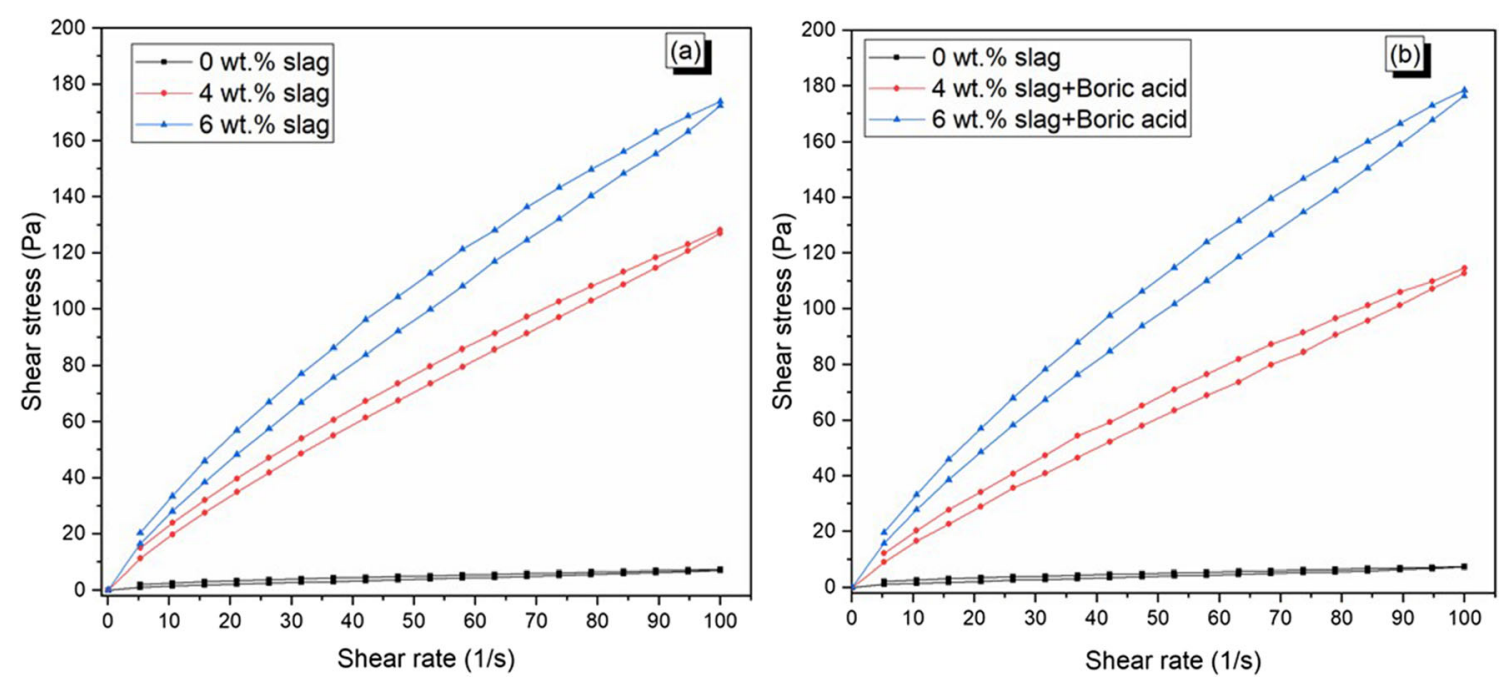

replacement. This result correlates with the inhibitor role played by boric acid in the setting time and reaction kinetics of the slag-blended volcanic ash-based phosphate geopolymer as shown in this work (see Figs. 2 and 3). Indeed, the competition between the dissolution of boric acid and slag-volcanic ash hinders the formation of high-volume reaction products. Consequently, the compressive strength of the slag blended is also diminished. Moreover, the water stability seems to be better than the mixes without boric acid, since the maximum strength loss here is around $22 \%$. Thus, it can be suggested that boric acid has taken part in the reaction formation of the binder and that a new phase including boron would have been formed. This will be ascertained and discussed further in the next sections of this paper.

\section{Mineralogy}

Figure 7 shows the X-ray patterns in the range of 5-65 $2 \theta$ of binders obtained with $4 \mathrm{wt} \%$ of slag and/or with the addition of boric acid. It should be noted that beyond that range, there is no more additional information from the spectra. All the initial minerals present in volcanic ash are still observed in the different binders. The main changes are the diminution of the peak intensity of some minerals

Fig. 4 Flow curves of slag blended (a) and mixed with boric acid (b) 


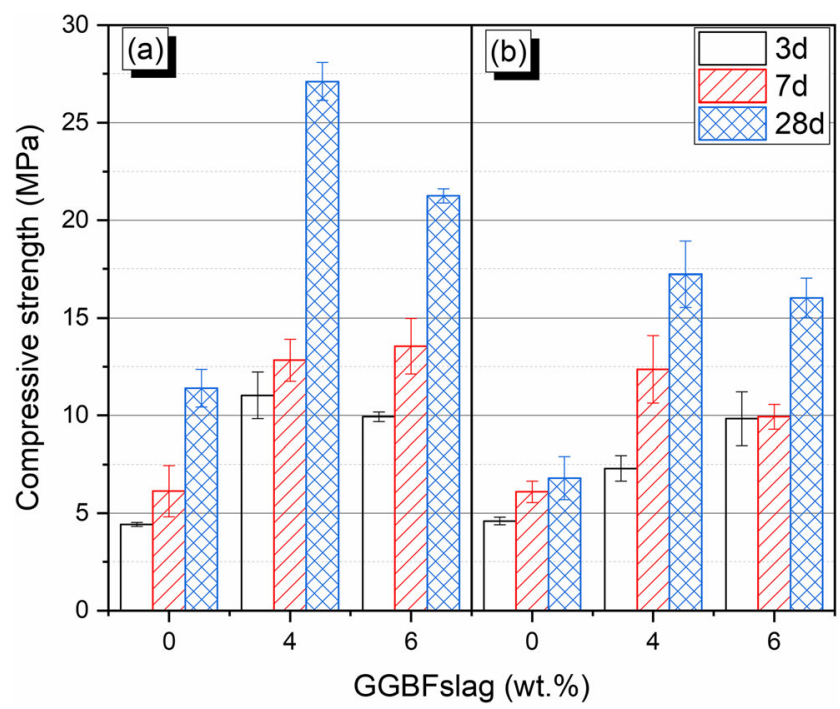

Fig. 5 Compressive strength evolution of slag-blended volcanic ashbased phosphate geopolymer (a), after immersion in water for $24 \mathrm{~h}$ prior measurement (b)

or their disappearance and the formation of the broad hump in synthesized cement paste in the range of 20 $40^{\circ}$. That hump is characteristic of amorphous reaction products. This indicates that minerals have taken part in the reaction, as demonstrated in previous works [3]. The reaction products were then characterized by thermal analysis as the XRD cannot detect X-ray amorphous phases. It is worth recalling that the amorphous phase is not stable at elevated temperatures, so the rise of temperature could trigger their crystallization which can indicate the type of phase or its composition.

The thermal analysis shows the differences in the mass change and heat flow with the increase of the temperature

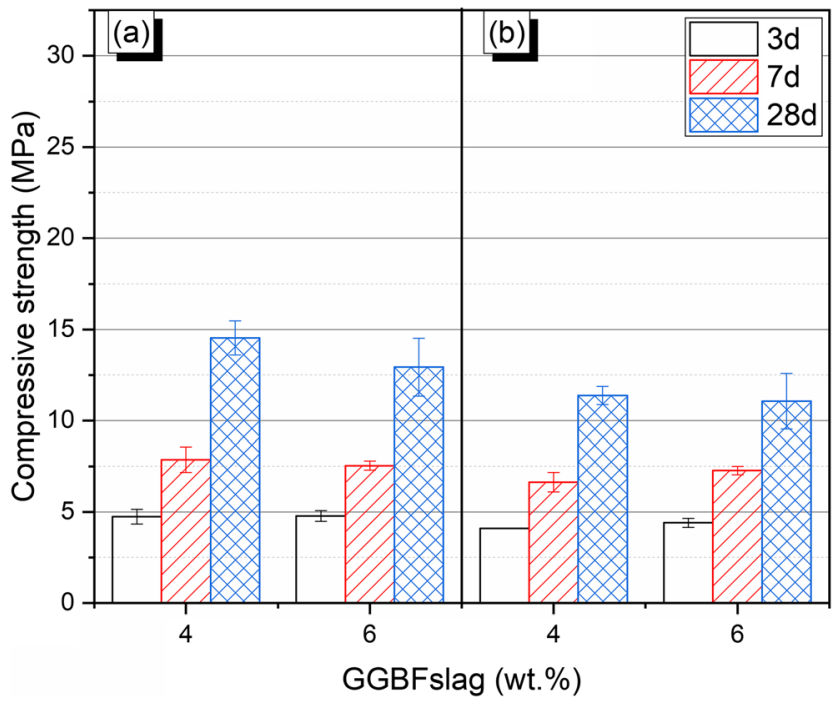

Fig. 6 Compressive strength evolution of blended slag-volcanic ashbased phosphate geopolymer with the addition of boric acid (a), after immersion in water for $24 \mathrm{~h}$ prior measurement (b)

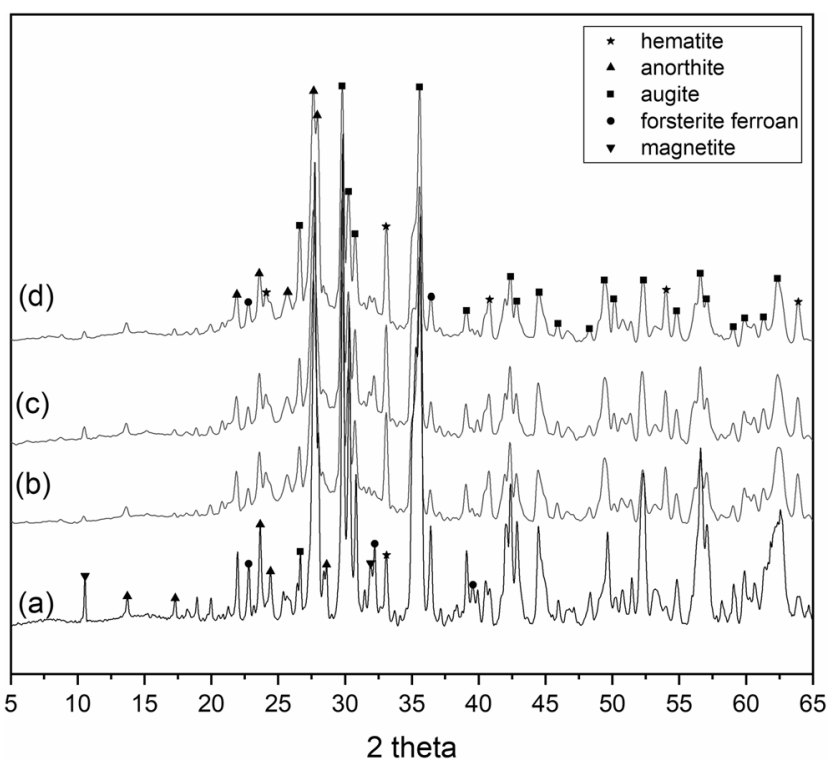

Fig. 7 XRD patterns of volcanic ash (a), volcanic ash-based phosphate geopolymer (b), volcanic ash-based phosphate geopolymer blended with 4 wt\% slag (c) volcanic ash-based phosphate geopolymer blended with 4 wt\% slag, and boric acid (d)

as observed in Fig. 8. Slag shows a very low mass loss starting at room temperature up to $650^{\circ} \mathrm{C}$ corresponding to the removal of residual water both physically and chemically bonded. This is followed by mass gain, which can be identified in the DSC curve $\left(700-850^{\circ} \mathrm{C}\right)$ as an exothermic peak and is due to the oxidation process of sulphites. Volcanic ash and phosphate geopolymer show a single mass loss which is accompanied by an endothermic peak with maximum appearing before $100^{\circ} \mathrm{C}$. That corresponds to the removal of different types of water [4]. In the phosphate cement, a very weak exothermic peak at around $650^{\circ} \mathrm{C}$ is identified which might be attributed to the transformation of amorphous iron phosphate phases from the binder into ferrous/ferric phosphate minerals [4].

\section{Microstructure and phase composition}

The SEM images of phosphate geopolymer with 4 wt $\%$ slag and/or boric acid are depicted in Fig. 9. The microstructure of all samples is heterogeneous with the presence of a few cracks. The EDX analysis of different samples reported in Table 4 helped to observe the diversity of the composition of the phases in different mixes. The asterisk put on the boron in Table 4 is to recall that the quantification of boron with EDX measurement is not accurate because it is a light element, so the molar ratio $\mathrm{B} / \mathrm{P}$ presented in Table 4 is only for the qualitative purpose to show how boron reacts in the system. In the samples without any additives, 3 distinct phases named A, B, and $\mathrm{C}$ were identified. The phase marked as $\mathrm{A}$ in the micrograph is silicon-rich corresponding to unreacted 

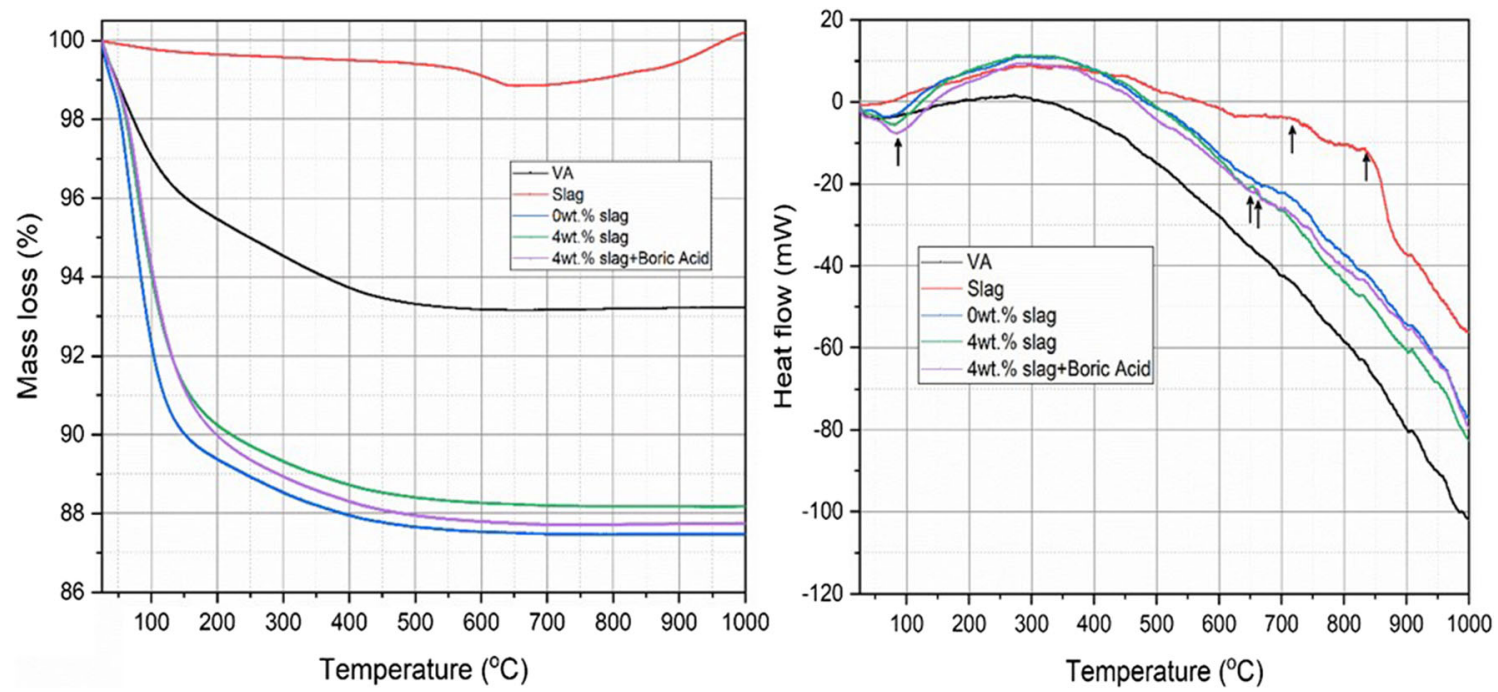

Fig. 8 Thermogravimetry and differential scanning calorimetry of volcanic ash, slag, and slag-blended volcanic ash-based phosphate geopolymer

particles of volcanic ash [3]. The phases B and C correspond to the newly formed binder. The composition of phase B shows that it is silicon and aluminum-free phase, while phase $\mathrm{C}$ is a mix-up of all elements present in volcanic ash in which atomic ratios with phosphorus allow its identification as the main binder phase. The latter was identified in all samples. The fact that the binders B and C are shapeless confirms that the reaction product is amorphous, as shown in the XRD.

The addition of slag leads to the formation of a single binding phase besides the unreacted particles. When boric acid is added to the previous mix, the resulting sample displays a new unreacted phase marked as AA whose composition includes boron with very low content of phosphorus. This suggests a possible formation of an intermediate unreacted phase of boron-volcanic ash particles which could be either physically or chemically bonded. Other new phases named D and $\mathrm{E}$ are present. Their chemical composition revealed that in phase $\mathrm{D}$, apart from all elements observed in phase $\mathrm{C}$, there is also boron with high content of phosphorus. This phase could result from the partial reaction of boric acid with the dissolved species during the formation of phase $\mathrm{C}$. The consequence of this is the lowering of the yield of reaction as discussed in the setting time and reaction kinetic in the previous section. This agrees with the previous statement and confirms the mechanism of the reaction of boric acid as described in this paper. The micrographs of the binder with $4 \mathrm{wt} \%$ slag + boric acid clearly show segregation between phase $\mathrm{C}$ and other phases, with a well-defined boundary. All these observations demonstrate that boric acid partly reacted with volcanic ash and slag while another part contributes to the formation of a new binder.

Table 4 EDX analysis of different phases identified in volcanic ash phosphate cement blended with 4 wt $\%$ slag and/or boric acid

\begin{tabular}{|c|c|c|c|c|c|c|c|c|c|c|c|}
\hline \multirow[t]{2}{*}{ Samples } & \multicolumn{9}{|c|}{ Atomic ratios } & \multirow[t]{2}{*}{ Area } & \multirow[t]{2}{*}{ Phases } \\
\hline & $\mathrm{Si} / \mathrm{P}$ & $\mathrm{Al} / \mathrm{P}$ & $\mathrm{Fe} / \mathrm{P}$ & $\mathrm{Ca} / \mathrm{P}$ & $\mathrm{Mg} / \mathrm{P}$ & $\mathrm{Ti} / \mathrm{P}$ & $\mathrm{Na} / \mathrm{P}$ & $\mathrm{K} / \mathrm{P}$ & $\mathrm{B}^{*} / \mathrm{P}$ & & \\
\hline \multirow[t]{3}{*}{$0 \mathrm{wt} \%$ slag } & 11.46 & 5.85 & 1.86 & 1.51 & 0.48 & 0.43 & 2.85 & 3.66 & 0 & A & Unreacted particles \\
\hline & 0 & 0 & 1.08 & 0.20 & 2.63 & 0.20 & 0.17 & 0.05 & 0 & $\mathrm{~B}$ & Binder 1 \\
\hline & 0.73 & 1.37 & 2.81 & 0.66 & 0.43 & 0.58 & 0.30 & 0.10 & 0 & $\mathrm{C}$ & Binder 2 \\
\hline \multirow[t]{2}{*}{$4 \mathrm{wt} \%$ slag } & 10.28 & 1.16 & 11.57 & 1.35 & 16.58 & 0.15 & 0.162 & 0.16 & 0 & A & Unreacted particles \\
\hline & 1.88 & 1.53 & 3.94 & 1.73 & 1.08 & 0.62 & 0.37 & 0.16 & 0 & $\mathrm{C}$ & Binder 2 \\
\hline \multirow[t]{5}{*}{$4 \mathrm{wt} \%$ slag + boric acid } & 6.35 & 1.63 & 2.91 & 4.50 & 6.22 & 1.84 & 1.28 & 0.81 & 1.73 & AA & Unreacted phase \\
\hline & 3.90 & 3.40 & 15.65 & 0.82 & 0.93 & 3.87 & 0.37 & 0.32 & 0 & A & Unreacted particles \\
\hline & 1.09 & 1.37 & 2.88 & 1.70 & 0.87 & 0.63 & 0.42 & 0.18 & 0 & $\mathrm{C}$ & Binder 2 \\
\hline & 1.55 & 1.30 & 2.38 & 1.32 & 0.58 & 0.26 & 0.35 & 0.17 & 0.68 & $\mathrm{D}$ & Binder 3 \\
\hline & 0 & 0.87 & 2.59 & 1.44 & 0.21 & 0.33 & 0.19 & 0.06 & 0.04 & $\mathrm{E}$ & Binder 4 \\
\hline
\end{tabular}



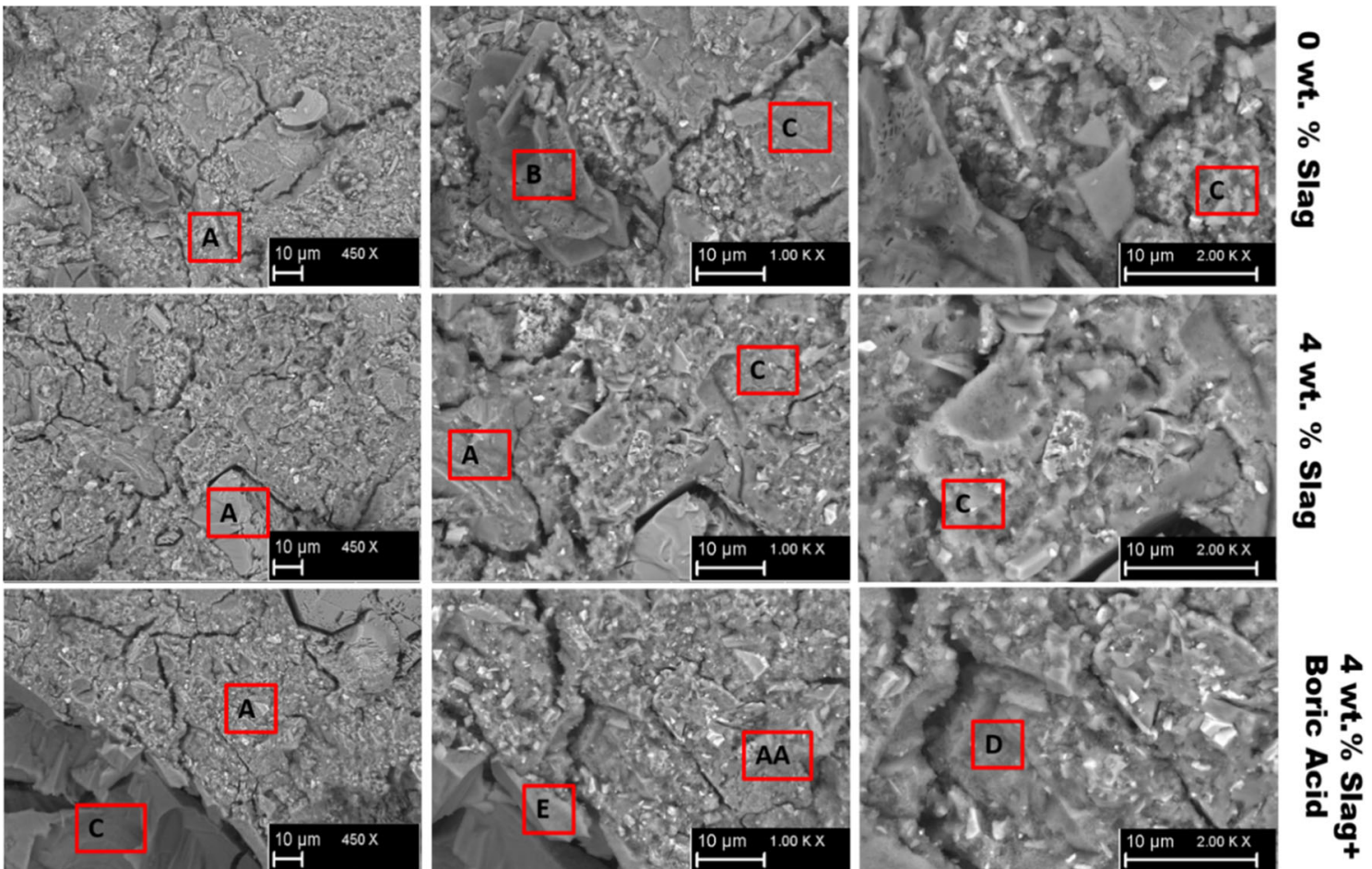

Fig. 9 Backscattered SEM images at different magnifications $(\times 450, \times 1000$, and $\times 2000)$ of volcanic ash-based phosphate geopolymer binder

\section{Conclusion}

The work has reported the role of blast furnace slag and boric acid addition on the reaction and strength development of volcanic ash phosphate cement. The main findings are summarized as follows:

- The partial substitution of volcanic ash with blast furnace slag speeds up the reaction kinetics of volcanic ash phosphate geopolymer binders.

- The addition of boric acid mainly contributes to the inhibition of the dissolution-precipitation reaction by consuming phosphate species.

- Although boric acid succeeded to delay the setting time and improves the fluidity of the paste, it was found detrimental for strength development.

- The compressive strength was significantly increased with the replacement of volcanic ash with blast furnace slag, while the incorporation of boric acid slows down the compressive strength development.

- The reaction products formed with the addition of slag and/or boric acid contribute to the improvement of the water stability of volcanic ash phosphate cement.

- The microstructure is composed of various types of binders including boron as proof of the partial reaction of boric acid with reacted phases from volcanic ash and blast furnace slag. Moreover, the unreacted boric acid also interacts with unreacted volcanic ash particles to form a new block of non-reacted phase.
Acknowledgements The technical assistance of Mr. Tobias Dorn and David Dahncke for collecting experimental test results is appreciated.

Author contribution Jean Noel Yankwa Djobo: research design, acquisition, analysis and interpretation of data, and drafting of the paper. Dietmar Stephan: advisor, critical revision and editing, and approval of the submitted and final versions.

Funding Open Access funding enabled and organized by Projekt DEAL. The authors received financial support from the Alexander von Humboldt Foundation through the Georg Foster Postdoctoral Fellowship (CM1201499-GF-P) awarded to Dr. Djobo.

\section{Declarations}

Conflict of interest The authors declare no competing interests.

Open Access This article is licensed under a Creative Commons Attribution 4.0 International License, which permits use, sharing, adaptation, distribution and reproduction in any medium or format, as long as you give appropriate credit to the original author(s) and the source, provide a link to the Creative Commons licence, and indicate if changes were made. The images or other third party material in this article are included in the article's Creative Commons licence, unless indicated otherwise in a credit line to the material. If material is not included in the article's Creative Commons licence and your intended use is not permitted by statutory regulation or exceeds the permitted use, you will need to obtain permission directly from the copyright holder. To view a copy of this licence, visit http://creativecommons.org/licenses/by/4.0/. 


\section{References}

1. Wagh, A.S.: Chemically Bonded Phosphate Ceramics: TwentyFirst Century Materials with Diverse Applications, 2nd edn. Elsevier Science, Amsterdam (2016) http://www.lavoisier.fr/ notice/fr406983.html

2. Wilson, J.W., Nicholson, A.D.: Acid-Base Cements. Their Biomedical and Industrial Applications. Cambridge University Press, New York (1993). https://doi.org/10.1007/bf02451742

3. Djobo, J.N.Y., Stephan, D., Elimbi, A.: Setting and hardening behavior of volcanic ash phosphate cement. J Build Eng. 31, 101427 (2020). https://doi.org/10.1016/j.jobe.2020.101427

4. Djobo, J.N.Y., Elimbi, A., Stephan, D.: Phase and dimensional stability of volcanic ash-based phosphate inorganic polymers at elevated temperatures. SN Appl Sci. 2, 828 (2020). https://doi. org/10.1007/s42452-020-2616-4

5. Bewa, C.N., Tchakouté, H.K., Rüscher, C.H., Kamseu, E., Leonelli, C.: Influence of the curing temperature on the properties of poly(phospho-ferro-siloxo) networks from laterite. SN Appl. Sci. 1, 1-12 (2019). https://doi.org/10.1007/s42452-019-0975-5

6. Katsiki, A., Hertel, T., Tysmans, T., Pontikes, Y., Rahier, H.: Metakaolinite phosphate cementitious matrix: inorganic polymer obtained by acidic activation. Materials (Basel). 12, 1-15 (2019). https://doi.org/10.3390/ma12030442

7. Wagh, A.S.: Phosphate geopolymer. In: Kriven, W.M., Gyekenyesi, A.L., Wang, J. (eds.) Dev. Strateg. Mater. Comput. Des. II Dev. Strateg. Mater. Comput. Des. II, pp. 91-103. John Wiley \& Sons, Inc, Hoboken, New Jersey (2011)

8. Wang, Y.-S.S., Alrefaei, Y., Dai, J.-G.G.: Improvement of earlyage properties of silico-aluminophosphate geopolymer using dead burnt magnesia. Constr Build Mater. 217, 1-11 (2019). https://doi. org/10.1016/j.conbuildmat.2019.05.050

9. Wang, Y.-S., Alrefaei, Y., Dai, J.G.: Influence of coal fly ash on the early performance enhancement and formation mechanisms of silico-aluminophosphate geopolymer. Cem Concr Res. 127, 105932 (2020). https://doi.org/10.1016/j.cemconres.2019.105932

10. Dong, T., Xie, S., Wang, J., Chen, Z., Liu, Q.: Properties and characterization of a metakaolin phosphate acid-based geopolymer synthesized in a humid environment. J Aust Ceram Soc. 56, 175-184 (2020). https://doi.org/10.1007/s41779-019-00376-w

11. Ben-Nissan, B.: Advances in calcium phosphate biomaterials. (2014). https://doi.org/10.1007/978-3-642-53980-0

12. Celerier, H., Jouin, J., Tessier-Doyen, N., Rossignol, S.: Influence of various metakaolin raw materials on the water and fire resistance of geopolymers prepared in phosphoric acid. J Non-Cryst Solids. 500, 493-501 (2018). https://doi.org/10.1016/j.jnoncrysol.2018.09.005

13. Wang, Y.-S., Provis, J.L., Dai, J.G.: Role of soluble aluminum species in the activating solution for synthesis of silicoaluminophosphate geopolymers. Cem Concr Compos. 93, 186195 (2018). https://doi.org/10.1016/j.cemconcomp.2018.07.011

14. Mo, L., Lv, L., Deng, M., Qian, J.: Influence of fly ash and metakaolin on the microstructure and compressive strength of magnesium potassium phosphate cement paste. Cem Concr Res. 111, 116-129 (2018). https://doi.org/10.1016/j.cemconres.2018.06.003

15. Wang, Y.-S., Dai, J.-G., Ding, Z., Xu, W.-T.: Phosphate-based geopolymer: formation mechanism and thermal stability. Mater Lett. 190, 209-212 (2017). https://doi.org/10.1016/j.matlet.2017.01.022

16. Wagh, A.S., Grover, S., Jeong, S.Y.: Chemically bonded phosphate ceramics: II, warm-temperature process for alumina ceramics. J Am Ceram Soc. 86, 1845-1849 (2003). https://doi.org/10.1111/j.11512916.2003.tb03570.x

17. Wagh, A.S., Jeong, S.Y.: Chemically bonded phosphate ceramics: III, reduction mechanism and its application to iron phosphate ceramics. J Am Ceram Soc. 86, 1850-1855 (2003). https://doi.org/10. 1111/j.1151-2916.2003.tb03571.x
18. Wagh, A.S., Jeong, S.Y.: Chemically bonded phosphate ceramics: I, a dissolution model of formation. J Am Ceram Soc. 44, 1838-1844 (2003)

19. Liu, R., Yang, Y., Sun, S.: Effect of M/P and borax on the hydration properties of magnesium potassium phosphate cement blended with large volume of fly ash. J Wuhan Univ Technol Mater Sci Ed. 33, 1159-1167 (2018). https://doi.org/10.1007/s11595-018-1948-z

20. Lahalle, H., Coumes, C.C.D., Mesbah, A., Lambertin, D., Cannes, C., Delpech, S., Gauffinet, S.: Investigation of magnesium phosphate cement hydration in diluted suspension and its retardation by boric acid. Cem Concr Res. 87, 77-86 (2016). https://doi.org/10. 1016/j.cemconres.2016.04.010

21. Yang, J., Qian, C.: Effect of borax on hydration and hardening properties of magnesium and pottassium phosphate cement pastes. J Wuhan Univ Technol Sci Ed. 25, 613-618 (2010). https://doi.org/ 10.1007/s11595-010-0055-6

22. Ribeiro, D.V., Paula, G.R., Morelli, M.R.: Effect of boric acid content on the properties of magnesium phosphate cement. Constr Build Mater. 214, 557-564 (2019). https://doi.org/10.1016/j. conbuildmat.2019.04.113

23. Li, B.I.D., Robayo-salazar, R.A., De Guti, R.M., Cyr, M., Elimbi, A.: Phosphoric acid activation of volcanic ashes: influence of the molar ratio $\mathrm{R}=(\mathrm{MgO}+\mathrm{CaO}) / \mathrm{P} 2 \mathrm{O} 5$ on reactivity of volcanic ash and strength of obtained cementitious material. J. Build. Eng. 33, 101879 (2021). https://doi.org/10.1016/j.jobe.2020.101879

24. Mahyar, M., Erdogan, S.T.: Phosphate-activated high-calcium fly ash acid-base cements. Cem Concr Compos. 63, 96-103 (2015). https://doi.org/10.1016/j.cemconcomp.2015.09.002

25. Djon, L., Ndjock, B.I., Baenla, J., Bike Mbah, J.B., Elimbi, A., Cyr, M.: Amorphous Phase of Volcanic Ash and Microstructure of Cement Product Obtained from Phosphoric Acid Activation. SN Appl, Sci (2020). https://doi.org/10.1007/s42452-020-2496-7

26. Qiao, F., Chau, C.K., Li, Z.: Calorimetric study of magnesium potassium phosphate cement. Mater Struct Constr. 45, 447-456 (2012). https://doi.org/10.1617/s11527-011-9776-z

27. Liu, Y., Qin, Z., Chen, B.: Influence of low-grade bauxite on the properties of magnesium phosphate cement. Constr Build Mater. 242, 118052 (2020). https://doi.org/10.1016/j.conbuildmat.2020.118052

28. Zribi, M., Samet, B., Baklouti, S.: Effect of curing temperature on the synthesis, structure and mechanical properties of phosphatebased geopolymers. J Non-Cryst Solids. 511, 62-67 (2019). https://doi.org/10.1016/j.jnoncrysol.2019.01.032

29. Kmecl, P., Bukovec, P.: Boron phosphate: its synthesis, gradual crystallisation and characterisation of bulk properties. Acta Chim Slov. 46, 161-171 (1999)

30. Mezger, T.G.: The Rheology Handbook, 4th edn. Vincentz Network, Hanover (2014)

31. Mehdizadeh, H., Najafi Kani, E., Palomo Sanchez, A., FernandezJimenez, A.: Rheology of activated phosphorus slag with lime and alkaline salts. Cem Concr Res. 113, 121-129 (2018). https://doi. org/10.1016/j.cemconres.2018.07.010

32. Liu, Y., Chen, B.: Research on the preparation and properties of a novel grouting material based on magnesium phosphate cement. Constr Build Mater. 214, 516-526 (2019). https://doi.org/10. 1016/j.conbuildmat.2019.04.158

33. Qin, Z., Ma, C., Zheng, Z., Long, G., Chen, B.: Effects of metakaolin on properties and microstructure of magnesium phosphate cement. Constr Build Mater. 234, 117353 (2020). https://doi. org/10.1016/j.conbuildmat.2019.117353

34. Xu, B., Lothenbach, B., Ma, H.: Properties of fly ash blended magnesium potassium phosphate mortars: effect of the ratio between fly ash and magnesia. Cem Concr Compos. 90, 169-177 (2018). https://doi.org/10.1016/j.cemconcomp.2018.04.002

Publisher's note Springer Nature remains neutral with regard to jurisdictional claims in published maps and institutional affiliations. 